\title{
Alcohol Withdrawal: Possible Risk of Latent Scurvy Appearing as Tiredness: A STROBE-Compliant Study
}

\author{
Christine Lux-Battistellia, c, Daniel Battistellia, b
}

\begin{abstract}
Background: Little is known about the prevalence of vitamin C deficiency in the population of individuals who are withdrawing from alcohol, and about possible consequences of latent scurvy. The aim of this study was to evaluate the prevalence of vitamin $\mathrm{C}$ deficiency in patients who were withdrawing from alcohol, its correlation with latent scurvy (mainly tiredness and weakness) and the change in the latter symptoms at 3 months after oral vitamin $\mathrm{C}$ supplementation.
\end{abstract}

Methods: A total of 47 patients (33 males, 14 females) who volunteered to undertake alcohol detoxification were included prospectively between January 2014 and November 2016. Determination of vitamin $\mathrm{C}$ blood levels was performed, and selected clinical signs of latent scurvy were recorded in a structured questionnaire. The decrease of tiredness after vitamin $\mathrm{C}$ supplementation was also studied 3 months after the inclusion of patients who had no other explanation for their weakness.

Results: About $57.44 \%$ of the patients were affected by vitamin C deficiency $(<11.4 \mathrm{~mol} / \mathrm{L})$. Less than one-third $(29.70 \%)$ had a normal plasma vitamin $\mathrm{C}$ level. There was a clear correlation between decreased vitamin $\mathrm{C}$ levels and the presence of tiredness $(\mathrm{P}=0.003)$ and no correlation between gum inflammation or purpura $(\mathrm{P}=0.97$ and 0.44 respectively). After 3 months of alcohol withdrawal and vitamin $\mathrm{C}$ supplementation, $89 \%$ of the patients reported a decrease of tiredness.

Conclusions: Vitamin C deficiency is prevalent in patients undertaking alcohol detoxification. Patients with this vitamin deficiency status often suffer from tiredness, which may be symptoms of latent scurvy. Even if tiredness is a highly nonspecific symptom, presence of fatigue should draw attention and the vitamin $\mathrm{C}$ level should be determined. Our preliminary data suggest that vitamin $\mathrm{C}$ supplementation, may decrease fatigue and improve patient's quality of life. This last evolution needs to be confirmed by a double-blind randomized study.

Manuscript submitted October 15, 2018, accepted November 20, 2018

${ }^{a}$ Nouvelle Clinique des Trois Frontieres, 8, rue Saint Damien 68300 SaintLouis, France

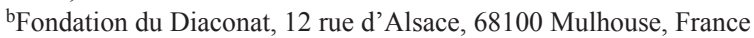

${ }^{c}$ Corresponding Author: Christine Lux-Battistelli, Nouvelle Clinique des Trois

Frontieres, 8, rue Saint Damien 68300 Saint-Louis, France.

Email: c.lux-battistelli@med3f.com

doi: https://doi.org/10.14740/jocmr3643
Keywords: Alcohol; Alcohol withdrawal; Scurvy; Vitamin C; Tiredness; Weakness

\section{Introduction}

Alcohol dependence is characterized by a chronic course, causing substantial individual suffering, a global burden of disease, and economic costs [1]. Among patients who underwent alcohol detoxification, 80-90\% will relapse within 6 months. Of these relapses, $50 \%$ occur within the first month after alcohol cessation [2]. Therefore, a target to meet is providing personalized and optimal treatment during and after detoxification.

Scurvy is often diagnosed by the state of well-established clinical signs such as skin and visceral purpura, gum involvement, and loss of healthy teeth [3, 4]. The WHO recognizes an early or "latent" form of scurvy, in which symptoms are nonspecific and mimic more common conditions such as weakness, leg pain and muscle ache; this form of early or latent scurvy is often underestimated [5-7]. These symptoms may also relate to depression [7]. Our attention was drawn by three cases of latent scurvy cured by vitamin C supplementation [6]. Therefore, we decided to study prospectively the prevalence of latent scurvy in patients who sought help for alcohol withdrawal and its association with clinical signs of scurvy, especially the latent form [5]. It also seemed interesting to track these clinical signs 3 months after vitamin $\mathrm{C}$ supplementation in patients for whom no other disease had been discovered that required medical transfer or a specific treatment.

\section{Patients and Methods}

\section{Study population}

This study was performed prospectively from January 2014 to November 2016 in patients who volunteered for alcohol detoxification even if they had prior complications of excessive alcohol consumption. Each patient provided written consent for the study and agreed to pay the cost of the determination of the plasma ascorbic level. Patients with confusion or who were in a coma due to complications of alcohol abuse were excluded.

Measurement of the vitamin C plasma level was per- 
Table 1. Clinical, Demographic and Biochemical Parameters of Enrolled Patients

\begin{tabular}{lll}
\hline & Males & Females \\
\hline Number & 33 & 14 \\
Age (years) & $57.97 \pm 12$ & $51.73 \pm 8$ \\
Body mass index $\left(\mathrm{kg} / \mathrm{m}^{2}\right)$ & $25.7 \pm 4.1$ & $25.2 \pm 6.9$ \\
AST $(\mathrm{IU} / \mathrm{L})$ & $70 \pm 54$ & $93 \pm 84$ \\
Gamma-GT (IU/L) & $251 \pm 262$ & $385 \pm 393$ \\
Corpuscular volume & $95.4 \pm 8.7$ & $101.1 \pm 8.4$ \\
Platelet count $\left(10^{9} / \mathrm{L}\right)$ & $189,393 \pm 91,053$ & $224,057 \pm 116,071$ \\
Prothrombin $(\%)$ & $90 \pm 13$ & $85 \pm 21$ \\
Albumin $(\mathrm{g} / \mathrm{L})$ & $40.1 \pm 5.3$ & $39.3 \pm 12.2$ \\
Hepatic ultrasonography & & $2 / 14$ \\
\multicolumn{1}{c}{ Normal } & $12 / 33$ & $7 / 14$ \\
\hline \multicolumn{1}{c}{ Steatosis } & $15 / 33$ & $4 / 14$ \\
\hline \multicolumn{1}{c}{ Compensated cirrhosis } & $4 / 33$ & $1 / 14$ \\
\hline
\end{tabular}

formed as soon as possible after the agreement, as discussions with a physician could lead to a change in dietary habits. Clinical signs, especially of latent scurvy, such as tiredness, leg pain or gum involvement, were recorded in a structured questionnaire during the first consultation. These symptoms have been noted in patients who did not think spontaneously to complain, unlike purpura, which was usually well observed by patients or nursing staff. All this was done before the laboratory results were known. All patients who were smokers received systematic otorhinolaryngology examinations to check for cancer. Other reasons for weakness were sought through clinical anamneses, physical examination, blood testing and abdominal ultrasound examination (Table 1).

Our first objective was to study the level of plasma vitamin $\mathrm{C}$ for patients who volunteered for alcohol detoxification and the possible role of sex, age and tobacco consumption.

The second was to investigate the correlation between the plasma vitamin $\mathrm{C}$ level and clinical signs of scurvy, including signs of latent scurvy such as tiredness.

The decrease or disappearance of tiredness after vitamin C supplementation was also studied 3 months later in patients who did not have another explanation for their weakness. This was assessed through a questionnaire asking patients if they felt as tired as before or if they felt better after vitamin $\mathrm{C}$ supplementation.

The study was approved by our institutional ethics committee and was conducted in accordance with the principles of the Declaration of Helsinki. Reporting of this study conforms to STROBE guidelines (Supplementary Table 1) (www.jocmr. org) [8].

\section{Laboratory methods}

Vitamin C was measured with high-pressure liquid chromatography (Cerba Laboratory, F-Cergy Pontoise), according to the method of Lee et al [9]. Plasma ascorbic levels reflected the recent intake and individual storage of vitamin $\mathrm{C}$.

Results were expressed in micromole per liter $(\mu \mathrm{mol} / \mathrm{L})$ with a normal range from 26.4 to $84.0 \mu \mathrm{mol} / \mathrm{L}$. These measures are in correlation with those quoted by $\mathrm{O}$. Fain et al for healthy French men and women ( 5 to $15 \mathrm{mg} / \mathrm{L}$ equal to $28.4-85.5$ $\mu \mathrm{mol} / \mathrm{L})[10]$. According to Johnston's criteria, a plasma vitamin C level lower than $11.4 \mu \mathrm{mol} / \mathrm{L}(2 \mathrm{mg} / \mathrm{L})$ was considered to be vitamin $\mathrm{C}$ deficiency and one lower than $28.4 \mu \mathrm{mol} / \mathrm{L}$ (5 $\mathrm{mg} / \mathrm{L})$ was vitamin $\mathrm{C}$ depletion [11]. The lower limit of quantification was $3 \mu \mathrm{mol} / \mathrm{L}(<0.5 \mathrm{mg} / \mathrm{L})$, at which a patient was considered biologically to have scurvy or be at high risk for the development of scurvy $[3,12]$.

\section{Statistical analysis}

Qualitative variables were described by frequencies and percentages, and quantitative variables were described by mean \pm standard deviation (SD) and range. Groups (males/females) were compared utilizing the Mann-Whitney rank sum test. Spearman's correlation coefficient test was used for identifying relationships among selected parameters (vitamin $\mathrm{C}$ level and age, vitamin $\mathrm{C}$ level and tobacco). Associations between tobacco use and sex and vitamin $\mathrm{C}$ levels were assessed by multivariable linear regression. Logistic regression analysis was used for studying correlation between decreasing vitamin $\mathrm{C}$ levels and tiredness, skin symptoms or gum inflammation. $\mathrm{P}$ $<0.05$ was considered the level of significance.

\section{Results}

During the investigation period, 51 patients volunteered for alcohol detoxification; 14 were female with a mean age of 51.71 \pm 8 (extreme 38 to 62 years) (range 24 ), and 37 were men with 


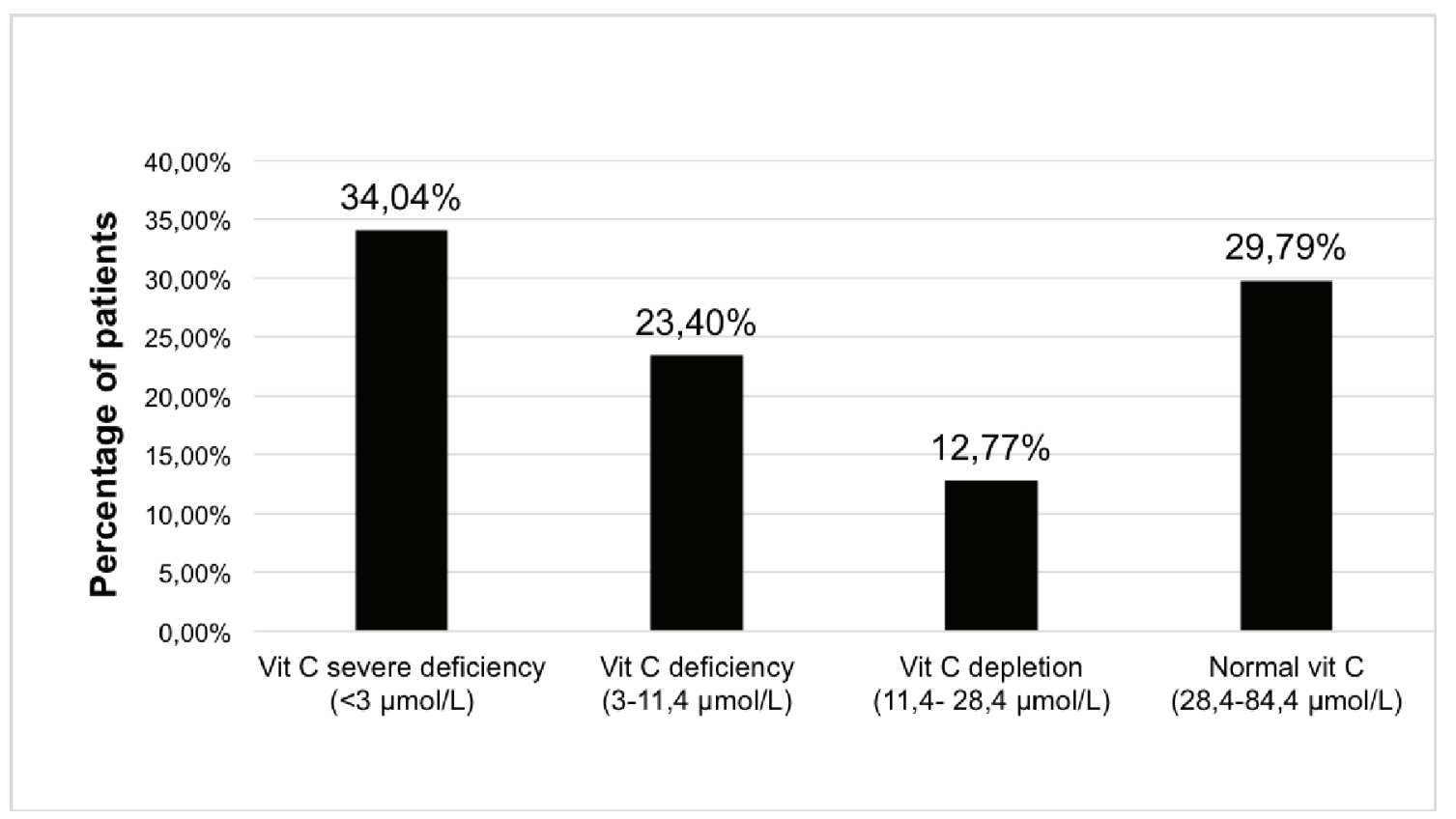

Figure 1. Distribution of plasma vitamin $C$ concentration in patients withdrawing from alcohol. Vitamin $C$ measures $(\mu \mathrm{mol} / L)$ : severe deficiency < $3 \mu \mathrm{mol} / \mathrm{L}$; deficiency: 3 - $11.4 \mu \mathrm{mol} / \mathrm{L}$; depletion: 11.4 - $28.4 \mu \mathrm{mol} / \mathrm{L}$; normal $>28.4 \mu \mathrm{mol} / \mathrm{L}$.

a mean age of $57.97 \pm 12$ (extreme 34 to 83 ) (range 49).

Three men refused the blood test, and one did not show up for the appointment. The mean age of the 33 remaining male patients was not affected: the mean age was 57.66, with the same SD (13) and the same range (range 49).

Therefore, 47 patients were included.

\section{Primary endpoint}

The prevalence of very severe deficiency $(<3 \mu \mathrm{mol} / \mathrm{L})$ was high and involved more than one-third of the patients (34.04\%). The addition of patients with vitamin $\mathrm{C}$ deficiency (3 - $11.4 \mu \mathrm{mol} / \mathrm{L}$ ) resulted in more than half of the patients being affected by vitamin C deficiency (57.44\%). Less than one-third of the patients had a normal plasma vitamin $\mathrm{C}$ level (29.70\%) (Fig. 1).

Pattern of deficiency was different between males and females, with males more often having severe deficiency and females more often having a normal concentration $(42.86 \%$ of females versus $21.21 \%$ of males) (Fig. 2).

Mean plasma vitamin $\mathrm{C}$ measurement for all patients was $19.5 \mu \mathrm{mol} / \mathrm{L} \pm 24.5$.

Mean plasma vitamin $\mathrm{C}$ measurement for males was 15.6 $\mu \mathrm{mol} / \mathrm{L} \pm 24.5$; mean plasma vitamin $\mathrm{C}$ measurement for females was $30.0 \mu \mathrm{mol} / \mathrm{L} \pm 28.8$. This difference was not statistically significant $(\mathrm{P}=0.08)$ (Fig. 3a).

There was no significant correlation between age and vitamin $\mathrm{C}$ measurement ( $\mathrm{P}=0.53)$ (Fig. 3b).

There appeared to be an inverse correlation between tobacco consumption and vitamin $\mathrm{C}$ levels $(\mathrm{P}=0.012)$ (Fig. $3 \mathrm{c})$.

After adjusting for tobacco consumption, the differences in vitamin $\mathrm{C}$ levels in males and females were not statisti- cally significant $(\mathrm{P}=0.064)$. Increasing tobacco consumption was inversely correlated with vitamin $\mathrm{C}$ levels in males $(\mathrm{P}=$ $0.0001)$ but not in females $(\mathrm{P}=0.59)$ (Fig. 4).

\section{Secondary endpoint}

The odds ratio of suffering from tiredness based on decreasing vitamin $\mathrm{C}$ levels is statistically significant $(\mathrm{P}=0.003)$. For every $10 \mu \mathrm{mol} / \mathrm{L}$ increase in vitamin $\mathrm{C}$ level, there is a $43 \%$ decrease in odds of weakness (95\% CI: $17 \%$ to $61 \%$ decrease in odds) (Fig. 5a).

The odds ratio of presenting purpura or petechiae based on decreasing vitamin $\mathrm{C}$ levels did not reach statistical significance $(\mathrm{P}=0.44)$ (Fig. 5b).

The odds ratio of presenting gum inflammation based on decreasing vitamin $\mathrm{C}$ levels did not reach statistical significance $(\mathrm{P}=0.97)$ (Fig. 5c).

There is a demarcation before and after the 34th patient, who was the first to have a normal vitamin $\mathrm{C}$ level (Fig. 6).

\section{Third endpoint}

The third objective was to study the decrease or disappearance of weakness or purpura in vitamin $\mathrm{C}$ deficient patients supplemented with $1 \mathrm{~g}$ /day of oral vitamin $\mathrm{C}$ for 3 months. This course after 3 months of vitamin $\mathrm{C}$ supplementation could be studied in only 18 patients due to patients' exclusion (Fig. 7).

The majority (16) (89\%) of these 18 patients reported a decrease or disappearance of tiredness or purpura at the end of the 3 months. Only two patients, who also drank alcohol again shortly after hospitalization, did not report improvement 

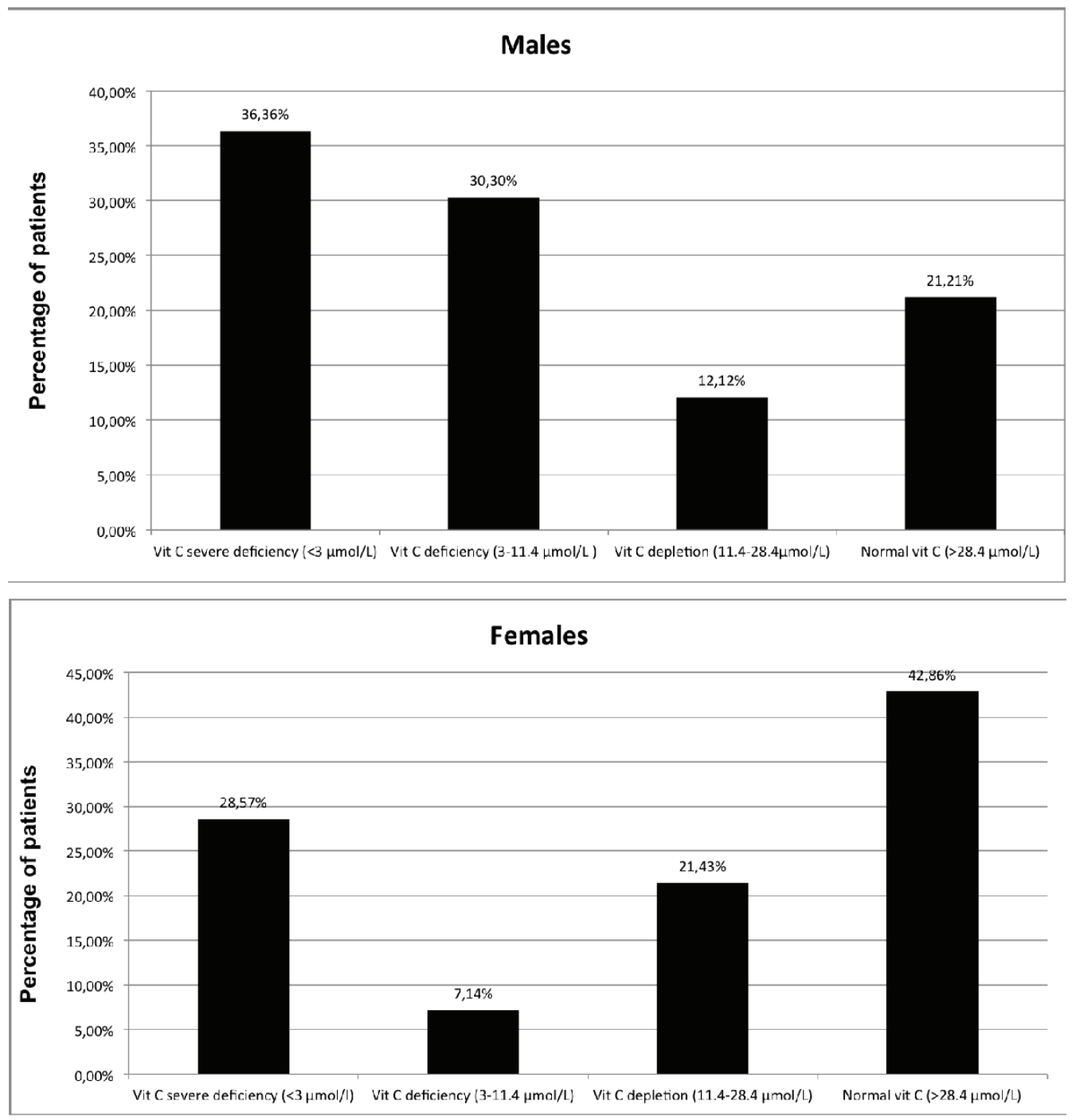

Figure 2. Distribution of plasma vitamin $C$ concentration in patients withdrawing from alcohol by sex. Vitamin $C$ measures $(\mu \mathrm{mol} / \mathrm{L})$ : severe deficiency < $3 \mu \mathrm{mol} / \mathrm{L}$; deficiency: 3 - $11.4 \mu \mathrm{mol} / \mathrm{L}$; depletion: 11.4 - $28.4 \mu \mathrm{mol} / \mathrm{L}$; normal $>28.4 \mu \mathrm{mol} / \mathrm{L}$.

in their weakness.

\section{Discussion}

Scurvy is an old disease that has been given many precise descriptions by ancient physicians, especially from the north of Europe, i.e., Bachstrom, Boerhaave, Lind. Boerhaave, in his "aphorisms", described the course of the disease in four steps, but he added that the symptoms did not appear exactly in the same order in each patient. He listed the symptoms as follows: "An unusual laziness, stiffness, an inclination to sit and lie down, a spontaneous weariness all over, a general heaviness, a pain of the muscles as after too great a fatigue, chiefly in the legs and loins, a great difficulty in walking chiefly up or down stairs, and in the morning upon first waking in all the limbs and muscles a sense of weariness and a smarting" [13].

The second and third steps are the well-known skin and visceral purpura, as well as gum involvement and the loss of healthy teeth. The fourth step, even with treatment, may lead to death $[12,13]$. More recently, the WHO recognized an early or "latent" form of scurvy characterized in part by lassitude, weakness and irritability [5].

Our study showed a very high prevalence $(57.44 \%)$ of vitamin $\mathrm{C}$ deficiency (below $11.4 \mu \mathrm{mol} / \mathrm{L}$ ) in patients volunteering for alcohol detoxification, with more than one-third having undetectable vitamin $\mathrm{C}$ levels and thus being considered at high risk for the development of scurvy.

This prevalence is far greater than that in the general population in France. In a study of 1,108 non-hospitalized subjects conducted in 1994 , only $12 \%$ of the men and $5 \%$ of the women had a vitamin $\mathrm{C}$ deficiency (below $11.4 \mu \mathrm{mol} / \mathrm{L}$ ) [14]. Very recently, in a cohort of 50-year-olds from New Zealand, only $2.4 \%$ had a plasma level indicating vitamin $\mathrm{C}$ deficiency [15]. Fain et al found a prevalence of $16.9 \%$ for vitamin $\mathrm{C}$ deficiency in patients hospitalized in a department of internal medicine 

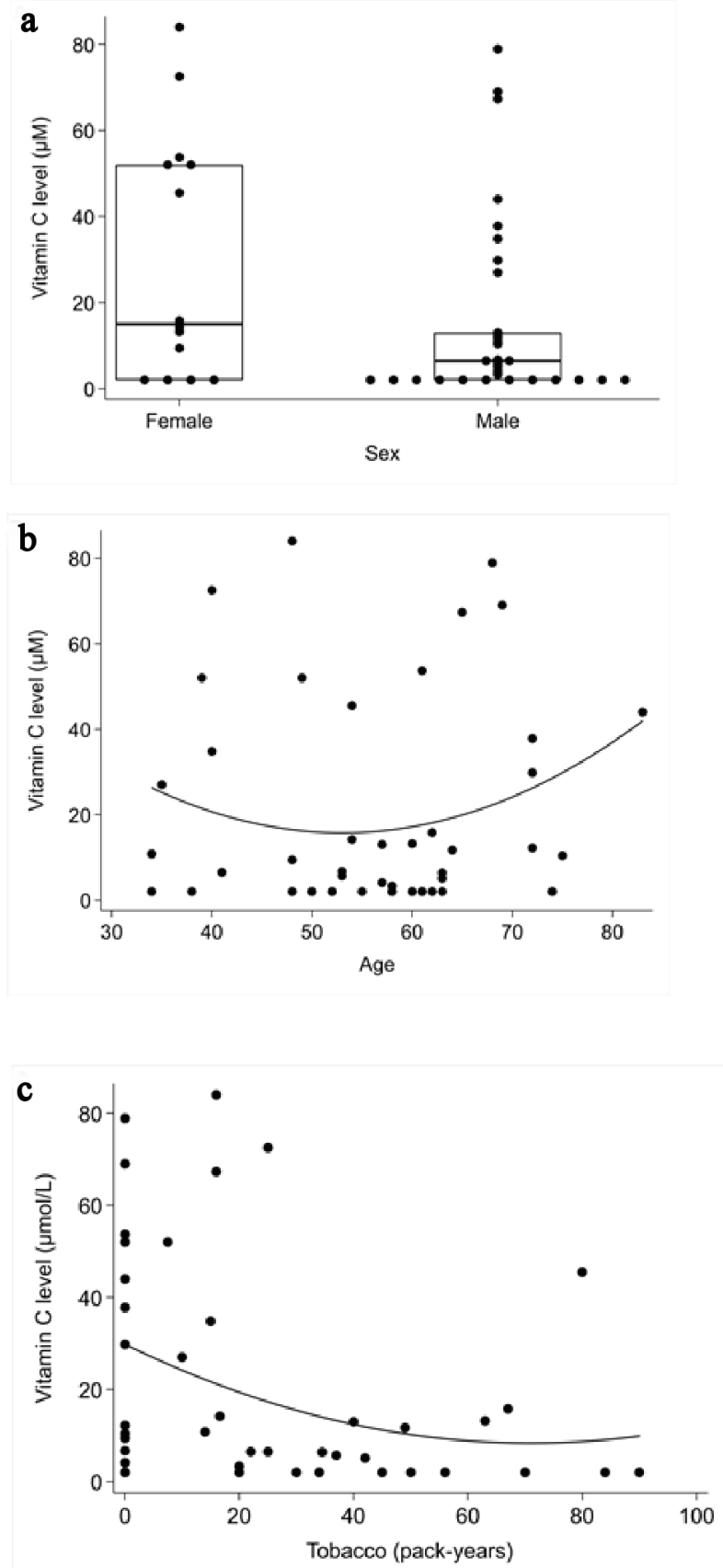

Figure 3. Correlation between plasma vitamin $\mathrm{C}$ concentrations and the role of the sex, age and tobacco consumption. (a) Mann-Whitney rank sum test: role of the sex Spearman's correlation coefficient test. (b) Role of age. (c) Tobacco consumption.

in France [10]. Our results are in line with those of another study in France concerning 87 individuals who were homeless for longer than 2 years; among them, $84 \%$ were patients with chronic alcohol use disorder, and $75.5 \%$ were smokers. Undetectable vitamin C levels (in this study $<6 \mu \mathrm{mol} / \mathrm{L}$ ) were found in $72 \%$ of cases and depletion in $95 \%$ [16]. In our study, if vitamin $\mathrm{C}$ depletion is included, these conditions were also found in $70 \%$ of the patients withdrawing from alcohol. How-

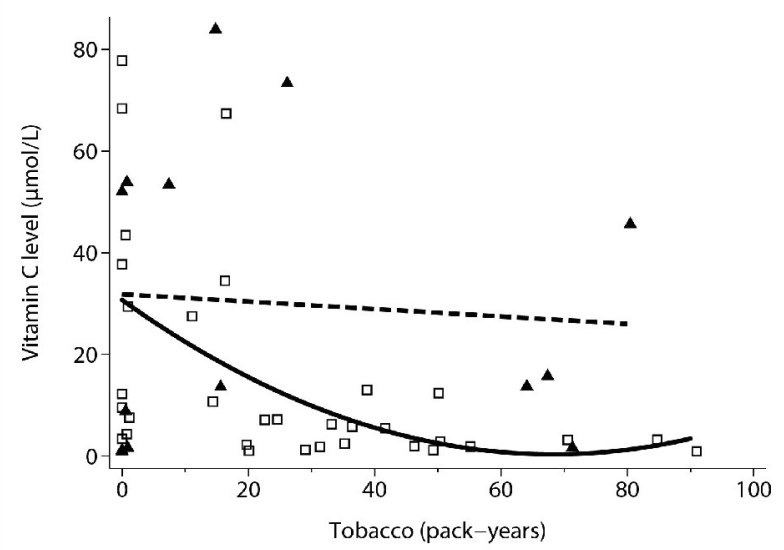

Figure 4. Association between tobacco consumption and sex and vitamin $\mathrm{C}$ concentrations by multivariable linear regression. Hollow squares: individual observations (males). Solid triangles: individual observations (females). Solid line: quadratic fit of vitamin $\mathrm{C}$ levels by tobacco use in males. Dashed line: linear fit of vitamin $\mathrm{C}$ levels by tobacco use in females.

ever, our patients had normal living conditions; only chronic alcohol abuse was a concern for all of them.

There are few recent studies investigating the relationship between heavy drinking and vitamin $\mathrm{C}$ intake. Among patients who were dependent on alcohol in the UK, $83 \%$ had low vitamin $\mathrm{C}$ intake. In this study, patients were ambulatory alcohol misusers, mostly single (50\%), unemployed (73\%) and from a lower social class [17]. In contrast, in German middle class males who consumed alcohol and had minor to moderately severe alcoholic liver disease (including compensated cirrhosis), vitamin $\mathrm{C}$ intake did not significantly differ from that in controls who did not consume alcohol [18]. However, even with a vitamin $C$ intake that was only slightly reduced compared to that of the controls, vitamin $\mathrm{C}$ plasma contents were significantly lower $(\mathrm{P}<0.017)$ in the patients who had an alcohol use disorder (mean value of $26.6 \mu \mathrm{mol} / \mathrm{L} \pm 20.6$ ) than in the controls $(65.5 \mu \mathrm{mol} / \mathrm{L} \pm 15.4)$ [18]. Regarding plasma vitamin $\mathrm{C}$ determination, these results are along the same lines as ours. These diminished vitamin $\mathrm{C}$ plasma contents could be explained by the fact that alcohol speeds vitamin $\mathrm{C}$ elimination [7], but also by the difficulty in obtaining a reliable dietary intake survey.

The inverse correlation between tobacco consumption and plasma vitamin $\mathrm{C}$ levels confirms the findings of prior studies: Cigarette smoking accelerates vitamin $\mathrm{C}$ catabolism, lowers its plasma and tissue concentrations and increases its nutritional requirement $[19,20]$. Although smoking has an influence, it is probably not the main variable of vitamin $\mathrm{C}$ deficiency in our study. Indeed tobacco consumption leads to a decrease in plasma vitamin $\mathrm{C}$ levels in males withdrawing from alcohol but not in females. Moreover several patients did not smoke and were biologically at high risk for the development of scurvy.

In the French healthy volunteers of the SU.VI.MAX study, plasma vitamin C concentration was also higher in females' volunteers. Among the variables that were possibly linked to plasma vitamin C level, estimated dietary intake was the first 

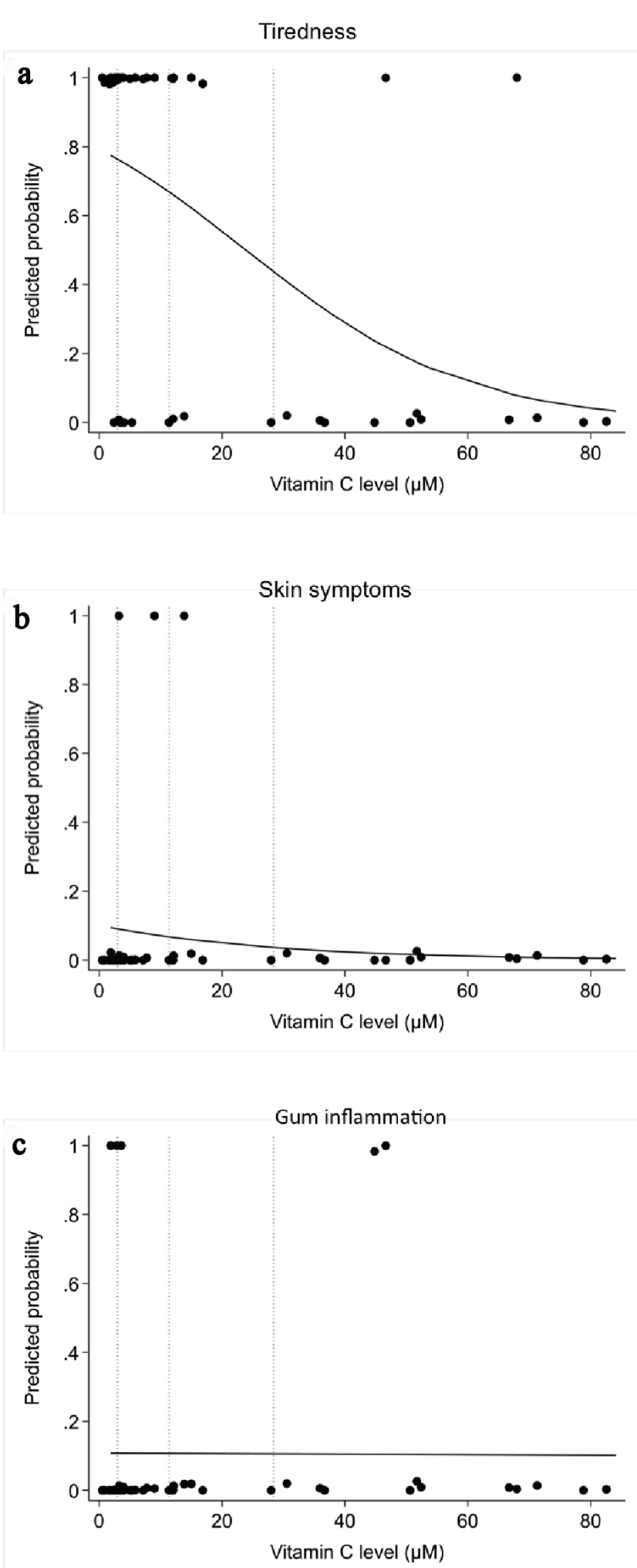

Figure 5. Correlation between plasma vitamin $\mathrm{C}$ concentrations and scurvy symptoms by logistic regression analysis: (a) tiredness or weakness; (b) skin symptoms; (c) gum involvement.
$(\mathrm{P}<0.0001)[21]$.

Concerning the second outcome, the correlation between low plasma vitamin $\mathrm{C}$ level and tiredness in otherwise quite young adults was statistically significant.

Fatigue was also the first symptom to appear, according to Crandon, aged 28, who experienced scurvy himself. To avoid interference from other vitamin deficiencies, he took a vitamin supplement that excluded vitamin C. Weakness was first noticed at about the end of the third month of vitamin C privation and increased with time. It was measured objectively by a test that demonstrated the severe disruption experienced during the vitamin $\mathrm{C}$ privation: he was only able to run for $16 \mathrm{~s}$, whereas following ascorbic acid therapy for 10 days at a dose of $1,000 \mathrm{mg}$ intravenously, he ran for $66 \mathrm{~s}$. This performance was poorer than the average of $270 \mathrm{~s}$ of men of his age. Even 7 weeks after vitamin $\mathrm{C}$ reintroduction, his performance was still lower at $84 \mathrm{~s}$. Concerning moderate work, Crandon could perform duration of $4.5 \mathrm{~min}$ during the scorbutic state, and the same duration 10 days later and 7 weeks later, meanwhile the average duration of the same work for men of his age was 15 $\min [22]$.

Hodges et al in "Experimental scurvy on man" also studied latent scurvy in four remaining prisoners who were in good health during the year 1966. Tiredness, especially of the lower limbs, and mild general malaise began insidiously. These symptoms were noticed in all four subjects and necessitated a reduction in their 10 miles of daily walking [23]. Moreover, 10 measures of the Fleishman physical fitness battery were used to assess potential changes in the discrete components of physical fitness. Impaired performance in measures of physical fitness occurred in those tasks that involved use of the legs [24].

Heavy drinking over a long period of time in our patients is compatible with an insidious deficit of vitamin $\mathrm{C}$ intake for months or years [25]. A few had a very low blood level of vitamin C without symptoms (Fig. 6). This is compatible with the notion of the high risk of the development of scurvy. According to Crandon, the drop in the plasma vitamin $\mathrm{C}$ level began 13 weeks before the first evidence of clinical scurvy, tiredness included, was manifest [22].

There was no statistical significant correlation between gum inflammation or purpura and plasma vitamin C level, which are the more symptoms of the beginning of manifest scurvy $[5,13]$. Moreover, gum involvement is not specific [26].

The third outcome, which studied the improvement or disappearance of lassitude 3 months after vitamin C supplementation, was strikingly high (89\%). This may allow us at least partially to impute the patients' tiredness to latent scurvy. The difficulty is that these early symptoms are common and not specific to the disease. For this reason, a diagnosis of scurvy is usually not performed until hemorrhagic findings are seen $[3,27]$.

By a placebo-controlled, depletion-repletion protocol, Johnston et al could demonstrate that even marginal vitamin $\mathrm{C}$ status $(<28 \mu \mathrm{mol} / \mathrm{L})$ in young people was associated with reduced work efficiency during submaximal exercise [28].

Even after 7 weeks of vitamin $\mathrm{C}$ reintroduction, the physical performance of Crandon was poorer than that of other men of his age [22]. This is the reason why we waited 3 months prior to evaluating the tiredness of our subjects after vitamin C 


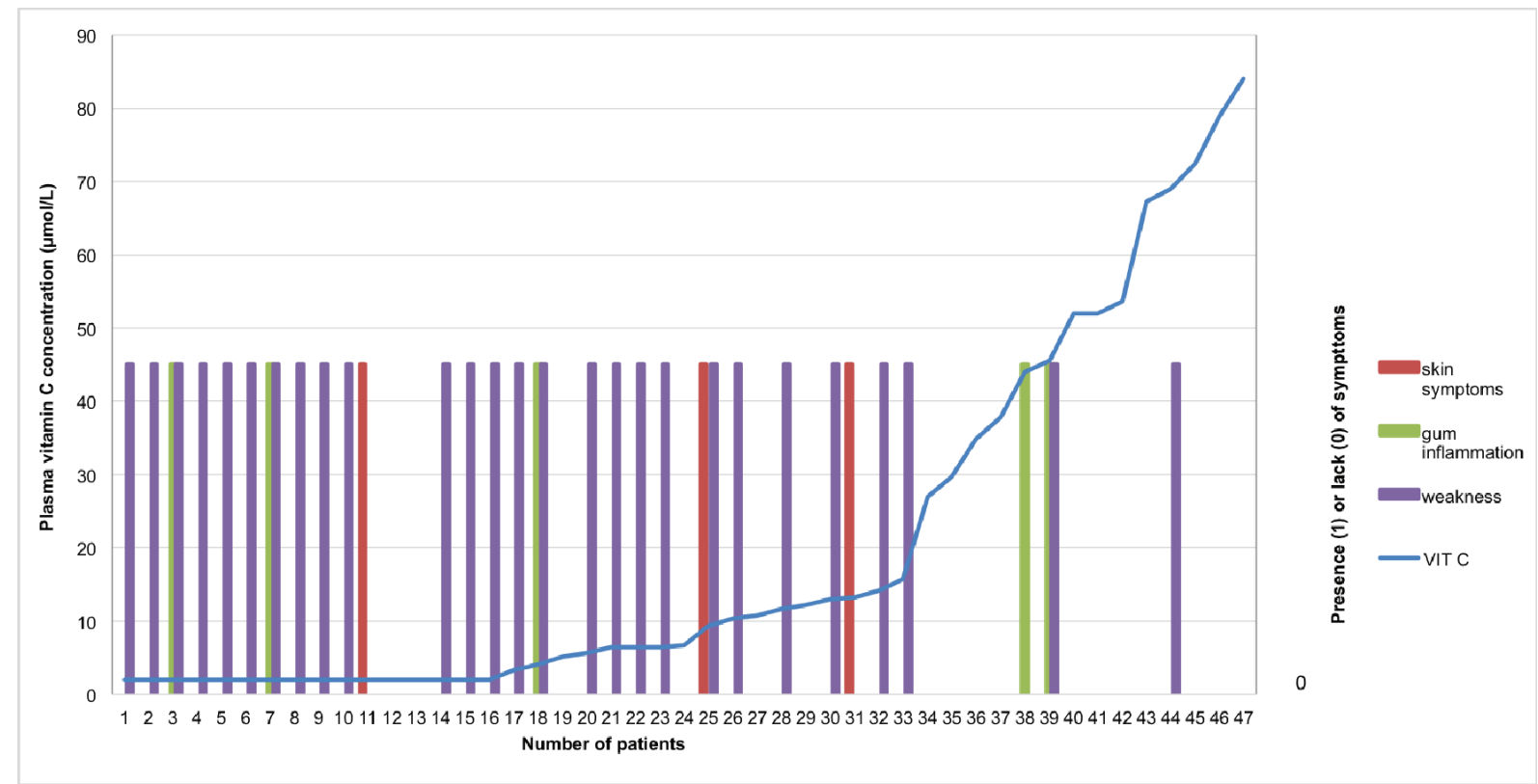

Figure 6. Correlation between plasma vitamin $\mathrm{C}$ concentrations and scurvy symptoms patient-individualized: In purple: tiredness or weakness; In red: skin symptoms (especially petechiae or purpura); In green: gum involvement. A transformation was applied to convert the status of tiredness, skin symptoms or gum involvement into binary variables. In regard to the binary variables: 0 corresponds to "absence of tiredness" whereas 1 means "presence of tiredness". The same applies for the other symptoms such as skin symptoms and gum involvement.

supplementation.

Vitamin $\mathrm{C}$ is required as a cofactor for hydroxylation of procollagen molecules, for tyrosine metabolism, for synthesis of peptides hormones, norepinephrine, and, for what is of interest to us, carnitine. Carnitine, which needs vitamin $\mathrm{C}$ for its hydroxylation, is an essential cofactor in the transport of long-chain fatty acids into the mitochondrial matrix. There- fore, it plays an important role in energy production via betaoxidation. It has been suggested that carnitine deficiency may provoke some of the earliest symptoms of scurvy, such as lack of energy and muscle aches, well before the appearance of defects in collagen synthesis [29].

Novel data on the effects of vitamin $\mathrm{C}$ depletion and dietary supplementation on human skeletal tissue ascorbate status

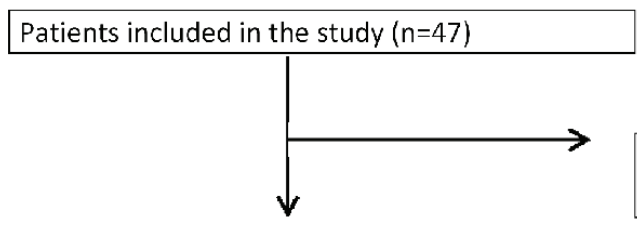

Patients deficient or depleted in vit $C(n=33)$

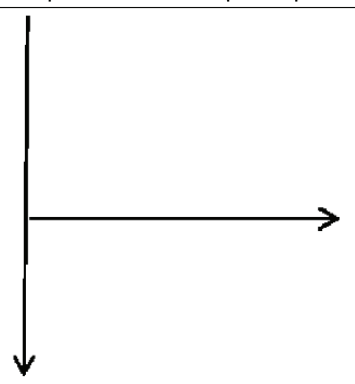

Patients included in endpoint $3(n=18)$
Excluded:

Vit $C$ level in normal range $(n=14)$

\section{Excluded:}

- no complaints or signs of latent scurvy $(n=5)$

- no other complaints of signs of scurvy than

loss of healthy teeth $(n=1)$

- concomitant cancer discovered $(n=7)$

- Early discharged patients due to

alcohol relapse during hospitalization $(n=2)$

Figure 7. Study design for endpoint 3: follow-up of latent scurvy symptoms in patients supplemented with vitamin C for 3 months. 
are provided by the study of Carr et al [30]. At baseline, mean plasma ascorbate concentrations of the study participants were marginally deficient, and their skeletal muscle tissue ascorbate levels were similarly low, with an approximately 3.5 -fold uptake of ascorbate by muscle tissue observed after a dietary intervention of consuming kiwi fruits. The authors concluded that a daily intake of vitamin $\mathrm{C}$ that provides plasma ascorbate concentrations $>50 \mu \mathrm{mol} / \mathrm{L}$ would maintain an optimal skeletal muscle ascorbate status.

There are some limitations to our study. One is that we had only a small number of patients. The second is the absence of a control group of the same age, since the measurement of vitamin $\mathrm{C}$ levels is not reimbursed in our country. Therefore, we used the reference ranges from the literature and from one of the two national reference laboratories. For the third endpoint, we did not measure the patient's tiredness by physical exercise, but we relied on medical interrogation of the patients about their improvement or lack thereof.

Our study has, however, several strengths. First, our study enrolled consecutive alcohol withdrawal patients over the course of 23 months. Second, all assessments were performed within a few days and by the same investigator. Finally, the high percentage of patients who were vitamin $\mathrm{C}$ deficient, the good correlation between their tiredness and the high percentage who experienced an improvement in this weakness after vitamin $\mathrm{C}$ supplementation deserve attention.

Guidelines for the management of patients undergoing alcohol detoxification recommend systematic vitamin B1 supplementation in order to prevent Korsakoff's and Wernicke's encephalopathy. However, little is said about vitamin $\mathrm{C}$ supplementation. Vitamin $\mathrm{C}$ is mentioned if there are clinical signs of scurvy or suspicions of malnutrition [31-33]. We emphasize that vitamin $\mathrm{C}$ deficiency is far more common than suspected in patients withdrawing from alcohol or those with alcohol use disorder.

Further studies are needed to confirm our findings, but clinicians should be aware of these signs of latent scurvy, about which patients, in the beginning, do not spontaneously think to complain, resigning themselves, instead, to their history of alcohol consumption. The medical team should ask if lassitude or weakness is present, and in that case, determine the vitamin $\mathrm{C}$ levels and start vitamin $\mathrm{C}$ supplementation for 3 months. In addition, last, but not least, nutritional advice regarding eating fresh fruits should also be given.

\section{Conclusions}

In conclusion, this STROBE-compliant study revealed that $70 \%$ of patients undergoing withdrawal from alcohol had a marginal status of vitamin C, with more than the half $(57.44 \%)$ exhibiting a deficiency status. Patients with an ascorbic acid deficiency status often suffer from weakness and tiredness, which are symptoms of latent scurvy and should not be neglected. Patients do not think to complain. Even if tiredness is a highly nonspecific symptom, presence of fatigue should draw attention and the vitamin $\mathrm{C}$ level should be determined. Our preliminary data suggest that vitamin C supplementation, may decrease fatigue and improve patient's quality of life. This last evolution needs to be confirmed by a double-blind randomized study.

\section{Acknowledgments}

The authors thank Mrs. Carol Ward for her help with the statistical analysis.

\section{Author Contributions}

CLB and DB planning and conducting study, DB recruiting patients and collecting data, CLB and DB interpreting data, CLB drafting manuscript, CLB and DB giving final approval.

\section{Financial Support}

None.

\section{Conflict of Interest}

None.

\section{References}

1. Rehm J, Mathers C, Popova S, Thavorncharoensap M, Teerawattananon Y, Patra J. Global burden of disease and injury and economic cost attributable to alcohol use and alcohol-use disorders. Lancet. 2009;373(9682):22232233.

2. Simioni N, Cottencin O, Guardia D, Rolland B. Early relapse in alcohol dependence may result from late withdrawal symptoms. Med Hypotheses. 2012;79(6):894895.

3. Levavasseur M, Becquart C, Pape E, Pigeyre M, Rousseaux J, Staumont-Salle D, Delaporte E. Severe scurvy: an underestimated disease. Eur J Clin Nutr. 2015;69(9):1076-1077.

4. Raynaud-Simon A, Cohen-Bittan J, Gouronnec A, Pautas E, Senet P, Verny M, Boddaert J. Scurvy in hospitalized elderly patients. J Nutr Health Aging. 2010;14(6):407410.

5. World Health Organization: Signs and symptoms; Classic scurvy. In: Scurvy and its prevention and control in major emergencies. 1999; p. 4 [Cited 2018 Aug 28] Available from: http://apps.who.int/iris/bitstream/10665/66962/1/ WHO_NHD_99.11.pdf.

6. Lux-Battistelli C, Battistelli D. Latent scurvy with tiredness and leg pain in alcoholics: An underestimated disease three case reports. Medicine (Baltimore). 2017;96(47):e8861.

7. Brown TM. Neuropsychiatric scurvy. Psychosomatics. 2015;56(1):12-20.

8. von Elm E, Altman DG, Egger M, Pocock SJ, Gotzsche 
PC, Vandenbroucke JP, Initiative S. The Strengthening the Reporting of Observational Studies in Epidemiology (STROBE) statement: guidelines for reporting observational studies. Lancet. 2007;370(9596):1453-1457.

9. Lee W, Roberts SM, Labbe RF. Ascorbic acid determination with an automated enzymatic procedure. Clin Chem. 1997;43(1):154-157.

10. Fain O, Paries J, Jacquart B, Le Moel G, Kettaneh A, Stirnemann J, Heron C, et al. Hypovitaminosis C in hospitalized patients. Eur J Intern Med. 2003;14(7):419-425.

11. Johnston CS, Thompson LL. Vitamin C status of an outpatient population. J Am Coll Nutr. 1998;17(4):366-370.

12. Doll S, Ricou B. Severe vitamin C deficiency in a critically ill adult: a case report. Eur J Clin Nutr. 2013;67(8):881882.

13. Boehrhaave H. Of the scurvy Aphorism 1151. In: Cowse $\mathrm{B}$, Innys W. Concerning the knowledge and cure of diseases Printed in London. 1715; p. 315-317. [Cited 2018 Aug 28]. Available via archive.org at: https://ia902605. us.archive.org/6/items/boerhaavesaphor00delagoog/boerhaavesaphor00delagoog.pdf.

14. Hercberg S, Preziosi P, Galan P, Devanlay M, Keller H, Bourgeois C, Potier de Courcy G, et al. Vitamin status of a healthy French population: dietary intakes and biochemical markers. Int J Vitam Nutr Res. 1994;64(3):220232.

15. Pearson JF, Pullar JM, Wilson R, Spittlehouse JK, Vissers MCM, Skidmore PML, Willis J, et al. Vitamin C status correlates with markers of metabolic and cognitive health in 50-year-olds: findings of the CHALICE cohort study. Nutrients. 2017;9(8):831.

16. Malmauret L, Leblanc J, Cuvelier I, Verger P. Dietary intakes and vitamin status of a sample of homeless people in Paris. Eur J Clin Nutr. 2002;56(4):313-320.

17. Manari AP, Preedy VR, Peters TJ. Nutritional intake of hazardous drinkers and dependent alcoholics in the UK. Addict Biol. 2003;8(2):201-210.

18. Bergheim I, Parlesak A, Dierks C, Bode JC, Bode C. Nutritional deficiencies in German middle-class male alcohol consumers: relation to dietary intake and severity of liver disease. Eur J Clin Nutr. 2003;57(3):431-438.

19. Lykkesfeldt J, Christen S, Wallock LM, Chang HH, Jacob RA, Ames BN. Ascorbate is depleted by smoking and repleted by moderate supplementation: a study in male smokers and nonsmokers with matched dietary antioxidant intakes. Am J Clin Nutr. 2000;71(2):530-536.
20. Northrop-Clewes CA, Thurnham DI. Monitoring micronutrients in cigarette smokers. Clin Chim Acta. 2007;377(1-2):14-38.

21. Faure H, Preziosi P, Roussel AM, Bertrais S, Galan P, Hercberg S, Favier A. Factors influencing blood concentration of retinol, alpha-tocopherol, vitamin $\mathrm{C}$, and betacarotene in the French participants of the SU.VI.MAX trial. Eur J Clin Nutr. 2006;60(6):706-717.

22. Crandon JH, Lund CC, Dill DB. Experimental human scurvy. N Engl J Med. 1940;223:353-369.

23. Hodges RE, Baker EM, Hood J, Sauberlich HE, March SC. Experimental scurvy in man. Am J Clin Nutr. 1969;22(5):535-548.

24. Kinsman RA, Hood J. Some behavioral effects of ascorbic acid deficiency. Am J Clin Nutr. 1971;24(4):455-464.

25. Maillot F, Farad S, Lamisse F. [Alcohol and nutrition]. Pathol Biol (Paris). 2001;49(9):683-688.

26. Liebana J, Castillo AM, Alvarez M. Periodontal diseases: microbiological considerations. Med Oral Patol Oral Cir Bucal. 2004;9(Suppl):82-91; 75-82.

27. Ben-Zvi GT, Tidman MJ. Be vigilant for scurvy in highrisk groups. Practitioner. 2012;256(1755):23-25, 23.

28. Johnston CS, Swan PD, Corte C. Substrate utilization and work efficiency during submaximal exercise in vitamin C depleted-repleted adults. Int J Vitam Nutr Res. 1999;69(1):41-44.

29. Rebouche CJ. Ascorbic acid and carnitine biosynthesis. Am J Clin Nutr. 1991;54(6 Suppl):1147S-1152S.

30. Carr AC, Bozonet SM, Pullar JM, Simcock JW, Vissers MC. Human skeletal muscle ascorbate is highly responsive to changes in vitamin $\mathrm{C}$ intake and plasma concentrations. Am J Clin Nutr. 2013;97(4):800-807.

31. Rolland B, Paille F, Gillet C, Rigaud A, Moirand R, Dano C, Dematteis M, et al. Pharmacotherapy for alcohol dependence: the 2015 recommendations of the French Alcohol Society, issued in partnership with the European Federation of Addiction Societies. CNS Neurosci Ther. 2016;22(1):25-37.

32. Alcohol-use disorders: diagnosis and management of physical complications | Guidance and guidelines | NICE [Internet]. [Cited 2018 Aug 28]. Available at https://www.nice.org.uk/guidance/cg100/chapter/ Recommendations\#acute-alcohol-withdrawal.

33. Kattimani S, Bharadwaj B. Clinical management of alcohol withdrawal: A systematic review. Ind Psychiatry J. 2013;22(2):100-108. 